\title{
Erratum to: Bone formation is suppressed with multi-stressor military training
}

Julie M. Hughes $\cdot$ Martha A. Smith • Paul C. Henning • Dennis E. Scofield •

Barry A. Spiering • Jeffery S. Staab · Jay R. Hydren · Bradley C. Nindl •

Ronald W. Matheny Jr.

Published online: 12 August 2014

(C) Springer-Verlag Berlin Heidelberg 2014

\section{Erratum to: Eur J Appl Physiol}

DOI 10.1007/s00421-014-2950-6

The author would like to correct the following error in the publication of the original article:

In the abstract, fourth sentence of the result section should read as:

25(OH)D increased significantly by $37.3 \pm 45.2 \%$ with training.

The online version of the original article can be found under doi:10.1007/s00421-014-2950-6.

J. M. Hughes $(\bowtie) \cdot$ P. C. Henning · D. E. Scofield ·

B. A. Spiering · J. S. Staab · J. R. Hydren · R. W. Matheny Jr. Military Performance Division, United States Army Research Institute of Environmental Medicine, 15 Kansas Street,

Building 42, Natick, MA 01760, USA

e-mail: julie.m.hughes17.ctr@mail.mil

M. A. Smith

Madigan Healthcare System, Joint Base Lewis-McChord,

Tacoma, WA, USA

B. C. Nindl

Army Institute of Public Health Army Public Health Command, Aberdeen Proving Ground, Aberdeen, MD, USA 